\title{
Uruguay: de los militares y la democracia
}

Silvia Dutrénit $B$.

El $1^{\circ}$ de marzo de 1985 Uruguay retoma el camino de la institucionalidad después de las elecciones recortadas de noviembre de 1984. Nuevamente el Partido Colorado, histórica dirección de la nación, recibe el voto mayoritario, ley de lemas mediante, ${ }^{\prime}$ y se hace cargo, por lo menos, de la ardua tarea de conducir el país hacia la ruta de la recuperación democrática. El 15 de marzo se liberan todos los presos políticos y se regresa a la vigencia de la constitución de 1967.

Es sabido que se llega a esta fecha luego de una negociación entre las Fuerzas Armadas (FF AA) detentadoras del poder desde 1973 y un grupo de políticos provenientes del Partido Colorado, la coalición de izquierda Frente Amplio (FA) y el minúsculo grupo de raiz católica Unión Cívica (UC). Entonces, el gran ausente fue el tradicional opositor de los gobiernos colorados: el Partido Nacional o Blanco. Pese a esta ausencia, que significaba en su momento la no concurrencia a la mesa de conversaciones de una parte del país, existía en el seno de la sociedad un consenso generalizado en torno a la necesidad de llegar a un acuerdo. Corresponde señalar aquí que a este sentimiento se arriba tanto por un rechazo al despotismo militar en el gobierno -aversión que viene de una cultura política basada en el antimilitarismo y el respeto a los derechos humanos- como por el fracaso de los proyectos intentados para solucionar la crisis económica.

Las características de la salida acordada son las que siguen: se convocaria a elecciones nacionales para el 25 de noviembre de 1984 con la finalidad de elegir todos aquellos cargos representativos estipulados en la constitución de 1967 y se transformaría el parlamento electo, a partir de julio de 1985, en una asamblea constituyente que dictaría una nueva carta magna, sustitutiva de la vigente antes del golpe de estado, para ser plebiscitada a fines del mismo aǹo. Se incorporaría en dicho proyecto constitucional la figura del "estado de insurrección" consistente en una suspen-

\footnotetext{
1 Es la legislación con finalidad electoral que ha sido convertida en la pieza clave de la política uruguaya. Sancionada en 1934, bajo la dictadura de Terra, en beneficio del bipartidismo, consistió en la constitucionalización de la heterogeneidad interna de los partidos con la existencia del lema o partido, en que se podian expresar diferentes alternativas políticas con sus candidatos respectivos, mediante sublemas para los mismos cargos, acumulando votos de cada uno en el Lema común en beneficio del candidato más votado dentro del partido. Con este instrumento legal el individuo más votado sólo respondia a su sector pero conseguia el triunfo con el apoyo de todos los sublemas restantes de su partido. La Ley de Lemas permite así la más diversa concepción programática y de postulantes a los cargos políticos dentro del mismo lema electoral. Ha constituido, a su vez, la herramienta para que se plasmen cambios en el equipo gobernante sin que varie el grupo hegemónico.
} 
sión discrecional, por el poder ejecutivo, de las garantías individuales ante sintomas de protesta o movimiento que atentasen, según él. contra el normal funcionamiento del nuevo ordenamiento juridico. También se incorporaria el Consejo de Seguridad Nacional (COSENA) como órgano asesor del ejecutivo en materia de "defensa nacional". y ya no como antaño de "seguridad nacional", y el ejecutivo designaria al comandante en jefe de cada fuerza (ejército. fuerza aérea y marina) de entre los tres oficiales generales más antiguos y a la vez, elegiria a estos últimos de una nómina propuesta por cada fuerza, de un número igual al doble de las vacantes existentes. Al mismo tiempo, se reduciría la jurisdicción militar para los "estados de guerra o de insurrección". Es asi como en materia institucional, se delinea lo que será su forma posdictatorial. Respecto a los derechos humanos se pacta liberar a los presos politicos que hayan cumplido más de la media pena y se deja abierta la posibilidad de que, una vez en funciones el gobierno civil. se podria legislar de inmediato una amnistía total. Las garantias individuales quedan aseguradas en los tĕrminos de la carta de 1967 y se instituye el derecho de amparo para defender otros derechos, además de la libertad personal.

De una rápida ojeada a lo que el Frente Amplio dice que se acordó. se advierte la ausencia del tema del enjuiciamiento de aquellos militares que hubieran cometido delitos de lesa humanidad y de la posible amenaza que significa introducir constitucionalmente las claúsulas reférentes al "estado de insurrección" para recuperar más tarde la democracia.

Conquistado el gobierno civil por la voluntad nacional y en pleno auge la politica de concertación entre todas las fuerzas políticas y sociales, comienzan a vislumbrarse los asuntos que serían materia de pronunciadas disputas. Surgirán las demandas, tantas veces postergadas, por mejores salarios y condiciones de vida y, en el plano politico, las exigencias de enjuiciar a los presuntos culpables de delitos contra los derechos humanos. Ambas reivindicaciones, que se serialan rápidamente, pero que son de difícil resolución para cualquier partido o coalición en el poder, han llevado al paulatino deterioro de las alianzas presentes en los comienzos del régimen democrático.

Una respuesta a la interrogante sobre cuáles son los desafíos que enfrenta hoy la democracia uruguaya, debe comenzar estableciendo con qué FF AA se negociaba a mediados de 1984. Si se hiciera un paralelo entre los militares, que veían ascender como presidente del Partido Colorado a su colega, el general Oscar Gestido, el 1 de marzo de 1967, y quienes cedieron el poder a los civiles en la persona del Dr. Julio Ma. Sanguinetti, habria que precisar algunos hechos:

La irrupción militar no extrana en la América Latina contemporánea pues desde los anoos treinta emergió como solución a los problemas políticos: sin embargo no se presentó en el Uruguay ante las crisis politicas sino hasta principios de los setenta. Esta diferencia muestra un perfil militar esencialmente profesional, ligado al mandato constitucional y ajeno a los reajustes del sistema politico.

- (\%. N. Schvars. "Uruguay: las barras del dia" en El Dia. México. 4 de julio de 1984. 
La visión generalizada que emanaba de la sociedad y que fue expandiéndose a lo largo del siglo una vez que se consolidaba un estado civilista y laico, definía a los militares como moradores de cuarteles, realizadores de desfiles y colaboradores en tareas de salvamento. Sin embargo el desarrollo histórico de las dos últimas décadas otorga al fenómeno militar rasgos distintivos, algunos de los cuales tienen que ver con la magnitud de las FF AA. Crecieron no sólo numéricamente, ${ }^{3}$ sino que utilizaron casi la mitad del presupuesto nacional, desarrollaron su propio sistema educativo, modernizaron su infraestructura y equipo, mejoraron su entrenamiento y extendieron sus vínculos con otras estructuras, instituciones y aparatos de Estado. Pero sobre todo, destaca el papel preponderante que en el quehacer político nacional han manifestado institucionalmente.

Este crecimiento de la magnitud institucional y política de las FF AA se dio en medio de un proceso progresivo de apoderamiento del aparato estatal. Primero, durante 1969-70, colaboraron en la represión y militarización de los empleados públicos en huelga, v.gr.; electricistas, telefonistas y bancarios oficiales; después, septiembre de 1971, fueron llamadas a participar en la lucha antisubversiva encabezada por el Estado Mayor Conjunto (policial militar) y. una vez declarado el "estado de guerra interno", abril de 1972, se convirtieron en conductoras y artífices de la represión antitupamara y en tribunal de sus propios prisioneros; por último, luego del golpe de estado, en junio de 1973, dirigieron paulatinamente la labor estatal en los frentes politicos del gobierno. La experiencia, fruto de una docena de años de infiltración en los más recónditos lugares de la estructura estatal, contribuyó a asignar a los militares el papel de gestores y hacedores de su propio proyecto politico. Este apareció con todo su fulgor después de la destitución del presidente Bordaberry en 1976.

Al mismo tiempo el instituto armado se fue depurando y adquiriendo un nuevo perfil ante los actores politicos. Su actuación, hasta junio de 1973, puede ser considerada como de "brazo armado de la oligarquía". para usar una caracterización convencional y reiterada hasta en sus propias declaraciones; posteriormente,

Liaguan: subdesarrollo y dapendencia. folleto publicado en el exterior por exiliados uruguayos. s. p. i.

4 Dice V. Bachetta: “Entre junio del 76 y julio del 77 . el régimen militar definió, a través de ocho actas. las bases de una nueva institucionalidad. El Consejo de la Nación y el Consejo de Seguridad Nacional (COSENA) fueron colocados por encima del Poder Ejecutivo. compuesto por el presidente y los ministros, y del Poder Legislativo, asignado al Consejo de Estado, al tiempo que se eliminó la tradicional independencia del Poder Judicial. creándose un Ministerio de Justicia. Por el Acta Institucional núm. 4 se prohibió el ejercicio de actividades políticas, incluyendo el derecho de voto. por el término de quince años. a los ocupantes de cargos públicos clegibles entre 1966 y 1973 de los partidos políticos. extendiéndolo a los candidatos no electos en el caso del Frente Amplio. El Acta Institucional núm. 5 estableció que la defensa de los Derechos Humanos e Individuales "debe regularse en función de la seguridad interna”. Y por las siguientes. se decretó la intervención de la Corte Electoral y la depuración del Registro Cívico. la libertad de la Administración para despedir a los funcionarios públicos y la impunidad jurídica de sus actos, por simple invocación del interes publico" o la "seguridad". Por último. en agosto de 1977. la dictadura anuncio la decisión de realizar elecciones presidenciales en 1981. con candidatos avalados por las fuerzas armadas. previa sanción de una nueva Constitucion a la cual se integrarian las normas establecidas por las actas institucionales".

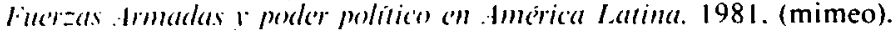


durante el gobierno civicomilitar. cobra fuerza la capacidad institucional para el manejo del Estado como resultado de una mayor cohesión interna y de una despolitización partidaria de sus cuadros y. finalmente. a partir de 1976. se plasma su nuevo papel de partido político sustituto.

La asunción de este nuevo papel supone el desplazamiento de los militares "profesionalistas" por aquellos que afirman la misión despolitizadora de las FFAA. Es decir, paradójicamente, proponen dirigir la actividad negándola: y a partir de dicha negación, conformar un nuevo discurso político. Asi es como las FF AA se despolitizan y autonomizan con respecto a la sociedad civil. ${ }^{5}$

A la hora de la negociación de 1984 idesde qué perspectiva juzgaban. quienes concurrieron a la mesa como representantes políticos. a la contraparte militar? Los puntos de vista de Sanguinetti y Seregni. sin duda alguna inspiradores y dirigentes de los personeros que dialogaron con los militares, son reveladores. Ambos reconocian que la única salida. en tanto que las FFAA detentaban el monopolio ce la fuerza y no podian legitimarse ante la sociedad. era la transacción. Sanguinetti decía antes del pacto en un editorial del 25 de mayo de 1984: "La negociación no puede conducir nunca a aceptar condicionamientos al poder democrático de los nuevos gobernantes. Asegurar una salida honorable a los militares, garantizar su profesionalidad, afirmar que no habrá revancha, son necesidades de la paz del país. pero no puede hacerse al precio de tergiversar el sistema institucional". 6

Por su parte el general Seregni una vez publicada el Acta Institucional núm. 19 que contenía los resultados del pacto realizado en el Club Naval y desproscrito el FA. valoraba:

Se obtuvo pues. que los militares no usurparán nuevos espacios de poder. sc consiguió que el próximo primero de marzo los militares vielvan a sus cuarteles. a su misión específica.

Se obtuvo y se afirmó que el presidente de la República es el jefe de las FF AA. y que es el que designa a los mandos militares.

$\mathrm{Y}$ esto, compañeros. después de 11 años de dictadura militar, significa un triunfo del pueblo y una derrota del poder militar.?

Desde los polos del espectro político nacional se caracterizaba a las fuerzas armadas que saldrían de la dictadura como pasibles de

Al respecto se resume de un articulo de J. Rial: "En 1973 un subgrupo, un cerdadero "partido militar". se adueño de las FF AA y eliminó a los militares "profesionalistas". Este sector se propuso conducir un proceso politico. negando la politica. asumiendo cl mando supremo como aconteció en otros regimenes autoritarios del Cono Sur. El régimen militar se caracterizó por la fuerte autonomización de las fuerzas armadas respecto de la sociedad civil y la actuación de éstas como "partido politico sustituto". de caracter único. durante todo el periodo. ante el receso de los partidos politicos. Sin embargo. esta pretensión de las FF AA de considerarse parte constitutiva e indivisible del poder político fue progresivamente rechazada por la sociedad. llegandose posteriormente a un acuerdo entre los partidos politicos y las fuerzas armadas para la salida del régimen autoritario... en esta negociación se impusieron garantias importantes que les permiten a las FF AA mantener fuertes niveles de autonomia dentro del aparato estatal". "Las FF AA. como Partido Politico Sustituto" en Nucier Sociedad, núm. 81, Caracas, enero/febrero. 1986 . p. 106.

Marcelo Pereira. 1980-1984: operarioin Sangminalii. Montevideo. CUI, 1985. (Seric Estudios).

Discurso de Liber Seregni en La Hora diario cooperativo. Montevideo. s. f. 
retornar a la "profesionalidad" y a la "misión especifica". La negociación se concibe entre partes con cuotas de poder político. Sin embargo no se advierte que los años que van de 1967 a ese 1984 ya habian desprofesionalizado a la institución y que ésta no sólo era propietaria de una cuota de poder sino que habia pasado de garante último de la razón de estado a ser su única poseedora.

Como se dijo, dos cuestiones espinosas, una por ausencia -el enjuiciamiento a los militares-y otra por aseveración -el estado de insurrección-, estaban minando, desde su origen, el desempeño de cualquier gobierno democrático. La segunda se resolvió, por exclusión, al reasumir la constitución de 1967. La primera, por inclusión. al promulgar una ley, aprobada mayoritariamente -el 22 de diciembre de 1986 - por la Asamblea Legislativa que afirma la renuncia a la caducidad de la capacidad punitiva del Estado respecto a los delitos contra los derechos humanos cometidos en cumplimiento de órdenes superiores durante el régimen de facto. Paradójicamente, el Partido Nacional que no concurrió a ratificar el acuerdo del Club Naval, propuso la ley que llenaba el vacio dejado por aquél. Ferreira Aldunate, su máximo dirigente, justificó asi su postura:

Se trata. pura y simplemente, de verse obligados, muy contra su voluntad. a reconocer que la impunidad por todas las violaciones de derechos humanos perpetrados durante la dictadura habia sido acordada en agosto de 1984 en el Club Naval. Por lo menos entonces, porque bien pudo haber sido antes. En cierto modo, asistimos a una especie de catarsis. o a un intento de exorcisar demonios que sin embargo se empeñan en seguir presentes en nuestra realidad cotidiana... Dejémonos pues de hacer y hacernos trampa. y digamos, con mucha vergüenza pero $\sin$ ambages, que de no sancionarse el proyecto de ley presentado por el Partido Nacional. el lunes pasado nos hubiéramos quedado sin instituciones. Es decir. sin nada. Otra vez sin nada. ${ }^{8}$

Todo estamento profesional, ergo las FF AA si se reconocen como tales, puede ser penetrado por la confrontación política. De alguna manera, quienes acordaron en el Club Naval, pensaron que esta premisa se cumpliria paulatinamente una vez que los militares retornaran a la rutina cuartelera. No es necesario, por ello, sugerir que se pactó algo más que lo expresado en el Acta núm. 19 ni formular conspiraciones militares para llegar tarde a la conclusión de que también el Partido Nacional puede participar en la supuesta contienda politica en el seno de los profesionales de las armas. Pero la afirmación de la profesionalidad recuperada es contradictoria a la violación del principio liberal de que un miembro de cierto grupo puede no ser juzgado por acusaciones que llevarian ante los jueces a cualquier otro tipo de ciudadanos.

¿Qué implicaciones tienen estos hechos para el futuro de la democracia uruguaya? Ningún acontecimiento reciente que involucre a los militares puede avalar que formen un estamento profesional. Si algo distingue al Estado de la sociedad, es su voluntad de ser Estado y de comprometer a las fuerzas armadas como su razón

\footnotetext{
"Wilson Ferreira. "Costo y recompensa de la grandeza" en La Democracia, Montevideo, 31 de diciembre de 1986.
} 
última de ejercerla. Si éstas, además, se han proyectado hacia la sociedad como partido, con cohesión y programas, violentan cualquier distribución del poder que pueda sustentar una democracia. No puede existir competencia democrática por el poder político cuando uno de los contenidos monopoliza la fuerza de las armas y cuenta con la garantía de la impunidad.

Hoy la afirmación de la democracia requiere reestructurar el poder mediante un nuevo reparto económico del excedente y ampliar la participación política en términos de la recuperación, ya no sólo electoral, del papel ciudadano. Esto último tiene que ver con la pertinente integración de los distintos estratos de trabajadores en las comisiones oficiales que atienden los temas laborales. En este sentido se ha retomado la política de coparticipación obrero-patronal-gobierno en las instancias de discusión y toma de decisiones. Sin embargo, las demandas vertidas en la mesa tripartita, en que se negocia, así como en otras que se hacen sentir desde diversos puntos del escenario donde se lleva a cabo la contienda politicosocial, son caracterizadas por el ejecutivo como elementos perturbadores y causas de la inestabilidad e inseguridad del proceso de recuperación democrática. Es claro que se presenten estas derivaciones del ejercicio democrático, que se tornan lógicas en la coyuntura uruguaya actual después de tantos años de cierre a la participación ciudadana. Pero su valor desde esta perspectiva, por lo menos, pone en duda los planes de extender la democracia y concuerda con el criterio dominante en las FFAA.

En medio de todo esto las fuerzas armadas juegan un doble papel: garantes de la seguridad nacional y componentes del juego de negociación política. En la medida que la institución militar se ha autonomizado y sendas funciones se robustecen, puesto que ejerciéndolas concretamente se escapan del control político, los sectores dominantes han generado hacia las mismas una postura que puede interpretarse como de relativa dependencia. Los acontecimientos últimos, a partir de ser presentada y aprobada la ley de impunidad, refuerzan tal razonamiento.

Frente a esta iniciativa, que se volvió mayoritaria en las Cámaras, se produce un cambio radical en la política de alianzas con la que se salió de la dictadura. Del extenso movimiento en que convergian los más disímiles sectores políticos, sociales y sindicales contrarios al régimen dictatorial -reunidos en aquel memorable acto de noviembre de 1983 ante más de la mitad de los habitantes de Montevideo- se pasó, pacto del Club Naval y ley de impunidad mediante, a una ruptura de la concertación política. Ahora, y a partir de una visión sobre las fuerzas armadas -quizás no distinta en cuanto a la "profesionalidad" y la "misión específica", pero sí diferenciada respecto a la idea de que debe juzgarse a quienes se encuentren responsables de delitos contra los derechos humanos y también en cuanto a la trascendencia de los procesos que se realicen para el desenvolvimiento democrático posterior-se produjo una división de toda la sociedad de importantes consecuencias ulteriores.

Con el convencimiento de que los juicios a los militares no sólo harian justicia sino que reforzarian el camino democrático, irrumpió en la escena política un movimiento que propuso una medida constitucional: convocar un referéndum que avalase plebiscitar la 
ley entre todos los ciudadanos. ${ }^{9}$ La iniciativa fue planteada primero por las viudas de los legisladores Zelmar Michelini y Héctor Gutiérrez Ruiz, asesinados en Buenos Aires en mayo de 1976 por comandos militares uruguayos y argentinos; de inmediato fue apoyada por el Frente Amplio, el Movimiento de Liberación Nacional (Tupamaros) y el Plenario Intersindical de Trabajadores (PIT-CNT). A pesar de la opinión contraria de los máximos lideres de los partidos tradicionales Blanco y Colorado el apoyo se hizo rápidamente extensivo a sectores destacados de los mismos. Del partido de gobierno se opone a la posición oficial y participa en el Movimiento Pro Referéndum, el grupo del diputado Vaillant. El importante Movimiento de Rocha dirigido por el senador Carlos Julio Pereyra, manifiesta clara y rotundamente su oposición a la postura oficial de su Partido Nacional. ${ }^{10}$

El referéndum muestra que se ha pasado de la política de concertación a la de confrontación en el seno del espacio democrático. Ello tiene implicaciones respecto a la política de alianzas y a la secular integridad bipartidista. La fisura creada en el Partido Nacional por el comportamiento de Carlos Julio Pereyra permite prever una dificil unidad futura.

Sin duda, la resolución del problema militar, una vez que la institución se ha convertido en fuerza política con proyecto propio, agobia hoy a los gobiernos emanados de la voluntad ciudadana en los paises del Cono Sur.

El espejismo bastante expandido de que el castigo a los militares devendrá en un resurgimiento de los regímenes autoritarios ha contribuido a otorgar una especie de garantia de impunidad a los futuros infractores. Por lo menos se puede apuntar que ha operado en esta conducta un cierto temor de los gobiernos democráticos ${ }^{11}$ al uso del castigo como forma ejemplar de lo que los abusos perpetrados durante las dictaduras merecen. Como se ha confirmado, sólo excepcionalmente militares de alto rango han sido desplazados de sus cargos de responsabilidad aun cuando hayan sido personeros de los regímenes de facto.

Esta actitud que se presenta como un poder compartido, sin solución de continuidad, y que se justifica en aras de salvaguardar las democracias, cuestiona el papel de las fuerzas armadas. Y esto en el caso uruguayo es todavía más palpable cuando se hace referencia a la historia de todo el siglo $x X$ en donde la función de las FF AA, hasta que se volvieron represoras del propio pueblo en aras de la seguridad del Estado, fue muy poco relevante. Su función o razón de ser, como garantes de la nación frente a posibles agresio-

\footnotetext{
Este recurso constitucional consiste en recoger el $25 \%$ de las firmas de quienes están habilitados para votar con el fin de someter a plebiscito una ley aprobada y vigente. En mayo de 1987. a escasos tres meses de haber comenzado la campaña por el referéndum. el Comité Nacional. encargado de la misma, anuncia públicamente que se cuentan ya con alrededor de $\mathbf{4 4 0} 000$ firmas que avalan la medida de las 550000 también aproximadas necesarias para cumplir con el requisito del $25 \%$.

"Al realizarse el congreso extraordinario del Movimiento de Rocha, en mayo de 1987, se reafirmó la posición con el consenso de los representantes al mismo. Entre otros pronunciamientos el Congreso proclamó por unanimidad la afirmación de la justicia como instrumento indispensable para la paz social. Cf. El Dia. Montevideo. 25 de mavo de 1987.

$"$ Véase Victor Sanz López, "Para que la noche quede atrás" en Fuerzas Armadas y democracia. op. cit., p. 117 y ss.
} 
nes externas, es un supuesto inexistente para el Uruguay contemporáneo, por lo cual surge por lo menos la inquietud de qué papel cumplen realmente. La historia de los últimos años manifiesta que las fuerzas armadas han actuado como disruptoras del curso democrático y practicantes efectivas de golpes de estado.

Toda propuesta que intente consolidar la democracia debe partir del diagnóstico del carácter actual de las FFAA. Si deben afirmarse los principios liberales para que se afiance la democracia, debería no sólo juzgarse a militares por los delitos cometidos sino despojar de toda legitimidad a las FF AA como grupo político que rompe la igualdad requerida para que se desarrolle la representación democrática. Para hacer justicia, se ha iniciado el camino constitucional consistente en que el $25 \%$ de los inscritos en el padrón electoral soliciten que la ley de caducidad de la facultad punitiva del Estado aprobada en diciembre sea sometida a plebiscito. Es decir, que el pueblo decida si deben o no juzgarse los presuntos culpables. Sin embargo, la solución del segundo aspecto del problema requiere volver a pensar lo sucedido y los cambios acaecidos en las FF AA y en la sociedad, como única forma de avanzar en el proceso democrático.

Mayo de 1987 